\title{
Ensino de ciências: $O$ enfoque CTS e a llha Interdisciplinar de Racionalidade (IIR)
}

Nely Soraya Bahia Souza nelysoraya@hotmail.com 0000-0003-4404-4219 Universidade Federal do Pará, Belém, Pará, Brasil.

Ana Cristina Pimentel Carneiro de Almeida

anacpca@ufpa.br

0000-0002-9432-2646

Universidade Federal do Pará, Belém,

Pará, Brasil.

\section{RESUMO}

A presente pesquisa de natureza teórica, realizada por meio de um estudo bibliográfico, tem como objetivo estimular o debate acerca de uma metodologia ainda pouco usual, a llha Interdisciplinar de Racionalidade (IIR). Nela, compartilho reflexões referentes ao ensino de ciências com ênfase no enfoque na Ciência, Tecnologia e Sociedade (CTS). Relato que, ao viajar entre os caminhos percorridos pelo ensino de ciências, encontrei algumas concepções pedagógicas que orientaram e outras que ainda orientam a metodologia, o currículo e a prática dos professores. Em busca de uma estratégia que satisfizesse meus anseios a respeito de estratégias de ensino que viabilizassem o ensino crítico e participativo, continuei a viagem e desembarquei na "plataforma" CTS, onde fui, gentilmente, convidada a me abrigar naquele espaço. Aceitei o convite e me propus a conhecer melhor as ideias daqueles que ali estavam; desfrutei do conhecimento de importantes personagens; aprendi bastante com os demais participantes e decidi então, na expectativa de, também, tornarme protagonista desse enredo, procurar algo diferente, que pudesse ajudar-me a encontrar respostas em como efetivar a alfabetização científica e tecnológica. Fui, nessa ocasião, apresentada às Ilhas Interdisciplinares de Racionalidade. Estratégia complexa? Talvez. Contudo, muito interessante e enriquecedora. Desta forma, dediquei-me a compreendê-la melhor e, neste artigo, compartilho as descobertas dessa agradável estadia nessa "plataforma", onde pude considerar que, além de ser uma metodologia desafiadora, o enfoque CST e a IIR mostram resultados valorosos para o atual cenário frente ao ensino de ciências, que almeja a formação de sujeitos capazes de interpretar o mundo em que vivem e tomar decisões fundamentadas a respeito de problemas sociais que também são de caráter científico.
\end{abstract}

PALAVRAS-CHAVE: Ensino de ciências. CTS. Ilha Interdisciplinar de Racionalidade. 


\section{INTRODUÇÃO}

A prática pedagógica do professor é produto da sua formação e da sua vivência enquanto aluno e professor. Constitui-se, também, por influência histórica relacionada às transformações políticas e sociais que orientaram e orientam os caminhos da educação. Nesse sentido, para compreender o professor de hoje é necessário voltar um pouco ao passado, buscando visualizar as raízes da problemática sobre o ensino de ciências encontradas nas salas de aulas atuais.

Ao observar historicamente o ensino de ciências, foi fácil perceber na literatura a forte influência sofrida por professores, ontem e ainda hoje, de pedagogias acríticas pautadas no conteúdo, na memorização e em metodologias que desconsideram o aspecto social da educação e da ciência. Talvez, por este motivo, mesmo hoje, as disciplinas como física, química e matemática são consideradas pelos alunos como difíceis e sem conexão com a realidade. Teixeira (2003), ao fazer esse retrospecto histórico, começando com jesuítas (de 1500 a 1759), com a Concepção Humanista Tradicional de ensino, passando pela Escola Nova (1924), até o Tecnicismo (1969 a 1979), coloca que:

[...] o ensino tradicional, o escolanovismo e o tecnicismo são propostas pedagógicas que não partem de uma análise acurada da sociedade, isolando o fenômeno educativo das questões sociais mais amplas, e dessa forma, tomam os problemas sociais como problemas acidentais, que atingem as pessoas individualmente, criando uma distorção da visão da escola, como instituição capaz de corrigir problemas dos indivíduos e atuando como instância de homogeneização social (TEIXEIRA, 2003, p. 92).

No que se refere ao ensino de ciências, o distanciamento entre a educação e os problemas sociais ficou mais evidente após o período da segunda guerra mundial, com a explosão da bomba atômica (1945), que expôs de maneira trágica tanto o conhecimento sobre a ciência e a tecnologia quanto as consequências trazidas por ele. Anos depois, o lançamento do Sputnik (1957) representou um grande marco no desenvolvimento científico e tecnológico.

A corrida espacial gerada nos anos de 1960 pela disputa política e econômica entre as duas superpotências no período da Guerra Fria passou a influenciar os currículos e, consequentemente, a didática para o ensino de ciências no resto do mundo. Dessa forma, adota-se esse evento como ponto de partida para iniciar as ponderações acerca do ensino de ciências.

Envolvido nesse contexto histórico das décadas de 1950/1960, o governo brasileiro, por intermédio do Ministério da Educação (MEC), adotou o projeto de reformulação do ensino de ciências proposto pela agência norte-americana USAID ${ }^{1}$. Naquele momento, o objetivo era fomentar o descobrimento e o aprimoramento de novas tecnologias. Os currículos estavam direcionados à formação de novos cientistas, tendo como características o ensino mecanicista, repetitivo e passivo, que pouco se preocupava com as consequências desse avanço tecnológico. Chassot (2004, p. 28-29) coloca que, "com isso, introduz-se uma rede de Centros de Treinamento de Ensino de Ciências no Brasil, visando implementar os projetos, já que a USAID tinha como meta uma ação mais direta nas escolas para conseguir delas maior eficácia para o desenvolvimento do país".

O modelo de ensino tecnicista perpetuou até a década de 1970 . Contudo, no final desse período, vários movimentos sociais reivindicavam não apenas a 
redemocratização do país, que enfrentava a ditadura militar (1964-1985), mas também questionavam o modelo de ensino vigente. Além disso, existia certo desinteresse pela formação nas áreas de caráter científico; o método de reprodução e experimentação já não atraía tantos jovens, o que se tornou preocupante diante da necessidade de formar novos cientistas. Segundo Nascimento, Fernandes e Mendonça (2010), nesse contexto, para superar os desafios impostos pela "guerra tecnológica", houve uma preocupação tanto com a aprendizagem dos conteúdos quanto com o desenvolvimento de habilidades científicas, no intuito de formar mão de obra cientificamente qualificada.

Percebe-se que a ciência é observada como objeto externo à sociedade. Comprovada por meio de verificações e traduzida em leis e postulados, assume uma postura positivista. $O$ reflexo desse pensamento no ensino de ciências é a sistematização do conhecimento científico, dirigida por um método reprodutivo, e, neste contexto, a escola torna-se mera transmissora do conhecimento e deixa de ser fomentadora para a construção do saber.

A ciência e a tecnologia foram e ainda são elementos que representam o poder: o poder de influenciar a política, a economia e a cultura dos demais países, sobretudo aqueles mais marginalizados. Deste modo, o domínio sobre a natureza e a criação de novas tecnologias é uma busca constante. Na visão tradicionalista, a ciência é detentora do saber, imutável e inegável; não pode ser questionada.

Krasilchik (2000) expõe que esse período marcante para o ensino de ciências influencia até hoje as tendências curriculares. Para romper com esses paradigmas, ainda na década de 1970 surge o movimento CTS (Ciência, Tecnologia e Sociedade), que propõe um novo olhar sobre a ciência e, consequentemente, sobre o desenvolvimento científico e tecnológico.

\section{DESEMBARCANDO NA PLATAFORMA CIÊNCIA, TECNOLOGIA E SOCIEDADE (CTS)}

As atuais pesquisas no campo do ensino de ciências estão, em grande parte, buscando novas estratégias metodológicas que auxiliem o processo de ensinoaprendizagem. Neste contexto, o ensino com enfoque CTS vem se destacando justamente por propor transformações no atual cenário. Para além de uma mudança metodológica, o ensino com enfoque CTS busca uma mudança no paradigma atual do ensino de ciências, o que Bazzo, Linsingen e Pereira (2003, p. 119) entendem como "uma reação acadêmica contra a tradicional concepção essencialista e triunfalista da ciência e da tecnologia, subjacente aos modelos clássicos de gestão política".

Comumente a sociedade deposita na ciência e na tecnologia a esperança de acabar com as mazelas sociais, melhorando a qualidade de vida, colocando fim na fome e na miséria. Assim, a ciência assume um papel salvacionista. Oriundo do movimento CTS, o ensino com enfoque CTS surge em contrapartida a essa ideia linear do desenvolvimento científico². "O movimento CTS surgiu, então, em contraposição ao pressuposto cientificista, que valorizava a ciência por si mesmo, depositando uma crença cega em seus resultados positivos" (SANTOS; MORTIMER, 2001, p. 96). Segundo Auler e Bazzo (2001, p. 1), os livros "A estrutura das revoluções científicas", de Thomas Kuhn", e "Primavera Silenciosa", de Rachel Carson", ambos publicados em 1962, "potencializaram as discussões sobre as interações entre ciência, tecnologia e sociedade". 
Decorrente das experiências negativas advindas do progresso científico e tecnológico, na década de 1960, diante de um cenário de guerra e de desastres ambientais, a sociedade, em especial as sociedades norte-americana e europeia, passou a se preocupar com as implicações oriundas desse desenvolvimento. Neste contexto, emerge o movimento CTS, no intuito de problematizar as consequências trazidas pelo progresso científico e tecnológico. Para Auler e Bazzo (2001, p. 2), "um dos objetivos centrais desse movimento consiste em colocar a tomada de decisões em relação à C\&T num outro plano. Reivindicam-se decisões mais democráticas (maior número de atores sociais participando) e menos tecnocráticas".

Um olhar crítico frente aos impactos negativos da tecnociência possibilitou uma tomada de consciência por parte da sociedade, que passou a questionar a neutralidade científica, explicitando que, apesar dos benefícios, ela é intencional e nem sempre os desdobramentos da ciência e da tecnologia são benéficos a todos. Desta forma, a sociedade passou a reivindicar uma mudança de postura frente aos problemas de caráter científico e tecnológico.

$\mathrm{Na}$ área da educação, mediante o denominado ensino com enfoque CTS ou abordagem CTS, esse movimento vem destacando-se cada vez mais. Cachapuz et al. (2008), Pereira e Maciel (2012) e Roehrig e Camargo (2013) indicam que nas últimas décadas houve um aumento significativo nas produções relacionadas à área de CTS ou CTSA. Segundo Pereira e Maciel (2012), no I ENPEC (Encontro Nacional de Pesquisa em Educação em Ciências), realizado em 1997, o número de produções era oito; em 2005, foram 38. No X ENPEC, realizado em 2015, os trabalhos relacionados à Alfabetização Científica e Tecnológica, enfoque CTS e CTSA e Educação em Ciências, totalizaram 64 (de um montante de 1.768) trabalhos aceitos.

Um fator determinante na adoção do enfoque CTS nas pesquisas educacionais está associado ao rompimento do paradigma tradicional de ensino. Deste modo, Santos e Schnetzler (2010) destacam alguns aspectos fundamentais para que ocorra esse rompimento, dentre os quais: A capacidade de participação e tomada de decisão; O conteúdo de caráter interdisciplinar; Abordagem do conteúdo contextualizado, incluindo temas sociais e problemas vinculados à ciência e à tecnologia; Procedimentos metodológicos em uma perspectiva construtivista; e $O$ planejamento e o desenvolvimento do processo de ensino-aprendizagem.

Em uma revisão bibliográfica, Auler (1998) verificou que, em relação aos objetivos, conteúdos, abrangência e modalidades de implementação do enfoque CTS, não há uma compreensão única. Auler e Delizoicov asseveram que:

O enfoque CTS abarca desde encaminhamentos que buscam contemplar interações entre CTS somente como fator de motivação, passando por aqueles que postulam como fator essencial uma compreensão crítica destas interações, até encaminhamentos que, levados ao extremo em alguns projetos, consideram secundária a abordagem de conceitos científicos (AULER; DELIZOICOV, 2006, p. 340).

Compreende-se, assim como Díaz, Alonso e Mas (2003) e Ricardo (2007), que o enfoque CTS também objetiva a Alfabetização Científica e Tecnológica na formação para a cidadania, sendo que "a alfabetização científica é a finalidade práticos pessoais, práticos sociais, para a própria cultura e para a humanidade" 
(DÍAZ; ALONSO; MAS, 2003, p. 82). Para Santos e Schnetzler, essa formação, mediante o enfoque CTS, "centra-se no desenvolvimento da capacidade de tomada de decisão por meio de uma abordagem que inter-relacione ciência, tecnologia e sociedade, concebendo a primeira como um processo social, histórico e não-dogmático" (SANTOS; SCHNETZLER, 2010, p. 73).

Percebe-se que um objetivo comum seria favorecer a atuação crítica sobre a ciência e a tecnologia por meio da alfabetização científica e tecnológica. Esse objetivo diz respeito à posição assumida diante da ciência e da tecnologia que cerca a sociedade. Silva e Araújo ressaltam a importância do enfoque CTSA ${ }^{5}$ na perspectiva de uma formação cidadã, pois, para os autores, "munir o educando com a ferramenta da pesquisa tende a possibilitar-lhe condições que facilitem o desenvolvimento de uma visão estruturada e crítica de seu meio, constituindo ao mesmo tempo uma forma de validar e aprimorar a prática pedagógica" (SILVA; ARAÚJO, 2011, p. 1).

Na perspectiva CTS, o sujeito, além de compreender a sua função enquanto cidadão e as implicações do desenvolvimento científico, tecnológico e social, tende a assumir essa função e toma pra si a responsabilidade de intervir nas questões sobre CT; "em outras palavras, pode-se dizer que o objetivo principal dos currículos CTS é o desenvolvimento da capacidade de tomada de decisão" (SANTOS; MORTIMER, 2007, p. 2). Santos e Mortimer (2001, p. 97) ressaltam isso em outro estudo, colocando que o "objetivo dos cursos CTS é capacitar os alunos para a tomada de decisão e para uma ação social responsável".

A tomada de decisão é um processo racional que implica na formação de atitudes e valores coerentes com uma postura crítica. Para isso, Santos e Mortimer (2001) realçam que é primordial a admissão de questões sociais referentes à ciência e tecnologia que envolvam a realidade do aluno. Essas são questõesproblemas que deverão ser examinadas e debatidas para que o aluno consiga propor uma solução.

O ensino com enfoque CTS propicia o desenvolvimento da capacidade crítica do aluno, ao ponto de permitir uma nova leitura de mundo, mediante a uma prática reflexiva, expondo que o conhecimento ultrapassa os conteúdos. O conhecimento, na verdade, é construído e reconstruído diante das situações ou questões-problemas; os conceitos científicos vão sendo apropriados à medida que o conhecimento e o conceito anterior já não satisfazem a resolução das problemáticas levantadas. Martins (2005, p. 62) lembra que "a sociedade que quer educar (para a ciência e pela ciência) tem, portanto, esse desafio: fornecer elementos para que os sujeitos possam dialogar com essa cultura, interpretando o mundo onde estão inseridos, em toda a sua complexidade".

Em grande parte, as presentes práticas de ensino não favorecem a atuação crítica, pois estão voltadas para o conteúdo, e não para uma ação social. Segundo Santos e Mortimer (2001), o processo de preparação do aluno para uma tomada de decisão decorre do letramento científico, que, para Krasilchik e Marandino (2007, p. 27), "significa não saber só ler e escrever sobre ciências, mas também cultivar e exercer as práticas sociais envolvidas com as ciências; em outras palavras, fazer parte de uma cultura científica".

Um obstáculo a ser superado no ensino de ciências é o distanciamento das disciplinas com a realidade do sujeito. É difícil para os alunos e, por vezes, até mesmo para os professores, perceberem a ciência para além das fórmulas, 
nomenclaturas, leis e postulados, típica do ensino tradicional. Essa visão torna o ensino de ciência descontextualizado e sem sentido. Além de provocar desinteresse, essa postura dificulta o processo de aprendizagem.

Nas estratégias com enfoque CTS, o professor procura integrar em suas aulas os interesses do aluno e aquilo que ele já sabe sobre determinado assunto, pois se compreende que o aluno é o ator principal no seu processo de formação. Essa atuação facilita a aproximação do conhecimento científico à realidade do aluno, não simplesmente evidenciando esse conhecimento, mas, sim, indicando caminhos para que o aluno se aproprie dele. Nesse sentido, Santos e Mortimer pontuam que:

\footnotetext{
Ao se pensar em currículos de ciência com o objetivo de formação para a cidadania, é fundamental que seja levado em conta o desenvolvimento da capacidade de tomada de decisão. Não basta fornecer informações atualizadas sobre questões de ciência e tecnologia para que os alunos de fato se engajem ativamente em questões sociais. Como também não é suficiente ensinar ao aluno passos para uma tomada de decisão (SANTOS; MORTIMER, 2001, p. 107).
}

Tal situação pode se tornar um desafio ao professor, pois o seu papel em sala de aula passa de detentor do conhecimento para mediador do processo de construção desse conhecimento. Há uma transposição no habitual método de ensino e tal transposição pode ser dificultosa de assumir, devido, principalmente, à sua formação inicial. Para suprir essa carência, Santos e Schenetzler (2010) pontuam a necessidade da formação continuada que inclua a concepção de ensino-aprendizagem construtivista e que desenvolva no professor uma atitude constante de investigação. Relembram, também, que, para a ocorrência de mudanças significativas, faz-se imprescindível a melhoria nas condições de trabalho do professor.

Deve ser tarefa contínua dos professores pensarem e repensarem inúmeras vezes como proceder diante de situações com as quais não estão habituados, mudar a prática docente, descobrir novas estratégias, reaprender e aprender novos assuntos e conceitos. É uma desconstrução para uma construção do ser professor formador e, sobretudo, é uma entrega, um ato de compromisso e responsabilidade com a profissão e com o futuro do outro.

\section{O ENCONTRO COM AS ILHAS INTERDISCIPLINARES DE RACIONALIDADE - IIR}

O enfoque CTS demanda uma estratégia de ensino. Brito e Gomes (2007) evidenciam quatro estratégias ${ }^{6}$ de ensino, conforme disposto na Figura 1 , que se deslocam do Ensino Tradicional para a Abordagem CTS. Mais recentemente, Brito (2016) destacou seis estratégias com o mesmo intuito, sendo elas: Ensino Através de Temas (EAT), a Aprendizagem Centrada em Eventos (ACE), a Metodologia de Projetos (MP), Aprendizagem Baseada em Problemas (ABP), os Três Momentos Pedagógicos (TMP) e as llhas Interdisciplinares de Racionalidade (IIR). A figura a seguir demonstra a ideia dos autores citados. 
Figura 1 - Características do ensino tradicional e da abordagem CTS

ENSINO TRADICIONAL

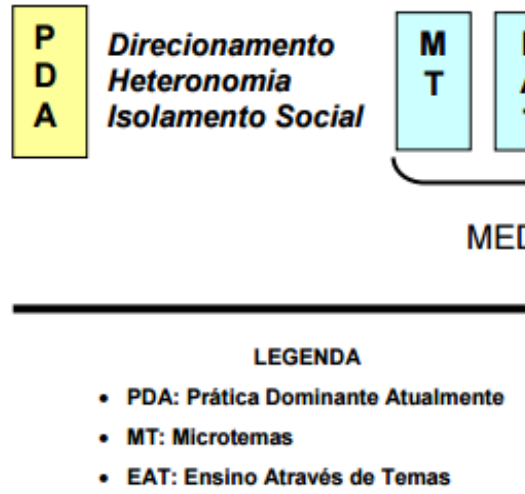

ABORDAGEM CTS

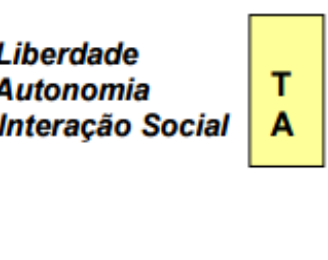

Fonte: Brito e Gomes (2007).

Dentre as estratégias apresentadas na Figura 1, vamos no ater às llhas Interdisciplinares de Racionalidade. Em sua essência, a IIR tem por finalidade a Alfabetização Científica e Tecnológica (ACT); contudo, pesquisadores como Ricardo et al. (2004); Díaz, Alonso e Mas (2003); Sousa (2007) e Sousa e Brito (2007) destacam diálogos possíveis entre o enfoque CTS e a Alfabetização Científica e Tecnológica (ACT). Segundo Díaz, Alonso e Mas (2003), para alcançar a alfabetização científica coerente com as necessidades pessoais e sociais do aluno, é desejável que o ensino de ciências esteja orientado pelas ideias CTS.

Assumindo que a IIR é uma estratégia condizente com os objetivos do enfoque CTS, nessa seção serão respondidas duas perguntas que muito foram feitas nos últimos tempos. Primeiramente, o que são llhas Interdisciplinares de Racionalidade? E, segundo: Por que as Ilhas? As respostas a essas perguntas estão correlacionadas. Em síntese, vale antecipar a informação sobre a opção em discorrer sobre IIR: por ser compreendida como uma metodologia, bem delineada, que pode auxiliar o professor a delimitar os passos em direção ao ensino mais democrático e reflexivo.

Utiliza-se o termo ACT baseado na concepção do Fourez et al. (1997), de acordo com a qual o sujeito alfabetizado científica e tecnicamente tem a capacidade compreender e decidir sobre situações científicas e tecnológicas. $\mathrm{Na}$ perspectiva ampliada de Auler e Delizoicov (2001), que se aproxima das visões de Paulo Freire, consideram que a alfabetização proporciona uma "leitura crítica do mundo", desmitificando os "mitos" ${ }^{8 "}$ sobre a relação ciência, tecnologia e sociedade. Em suas colocações, Chassot entende a ciência como uma linguagem, sendo assim, "ser alfabetizado científica e tecnologicamente é saber fazer ler a linguagem em que está escrita a natureza. É um analfabeto científico aquele incapaz de uma leitura do universo" (grifos nossos) (CHASSOT, 2007, p. 29).

Evidencia-se que a ACT, aliada ao enfoque CTS, favorece a consciência crítica sobre a ciência, a tecnologia e a sociedade; concordando com Auler e Delizoicov (2006, p. 338), ao considerarem que, para uma leitura crítica da realidade, é "fundamental uma compreensão crítica sobre as interações entre CTS, considerando que a dinâmica social contemporânea está fortemente marcada pela presença da CT". Para Fourez et al., a ACT possui três finalidades: "a autonomia do indivíduo (componente pessoal), a comunicação com os demais (componente cultural, social, ético e teórico), e um manejo do meio (componente econômico)" 
(FOUREZ et al., 1997, p. 61), o que também pode ser evidenciado nas práticas sob o enfoque CTS, pois, segundo Sousa e Brito (2007, p. 11), "o movimento CTS e ACT exigem uma nova cultura escolar, um comprometimento com novas bases pedagógicas e epistemológicas".

Nesse contexto, destacam-se as Ilhas Interdisciplinares de Racionalidade como estratégia de ensino com enfoque CTS, que proporciona a formação do aluno através da Alfabetização Científica e Tecnológica - ACT. Fourez et al. (1997, p. 62) consideram que o sujeito alfabetizado científica e tecnologicamente possui certa autonomia, que permite a ele "negociar as suas decisões frente às pressões naturais ou sociais", além de favorecer a capacidade de comunicação, de domínio e de responsabilidade. É importante destacar que, para compreender melhor as discussões relativas à avaliação das IIR, faz-se necessário conhecer o processo de sua construção.

A figura 2 foi elaborada por Pietrocola e Alves Filho (1998) para ilustrar uma Ilha Interdisciplinar de Racionalidade.

Figura 2 - Metáfora de uma Ilha de Racionalidade

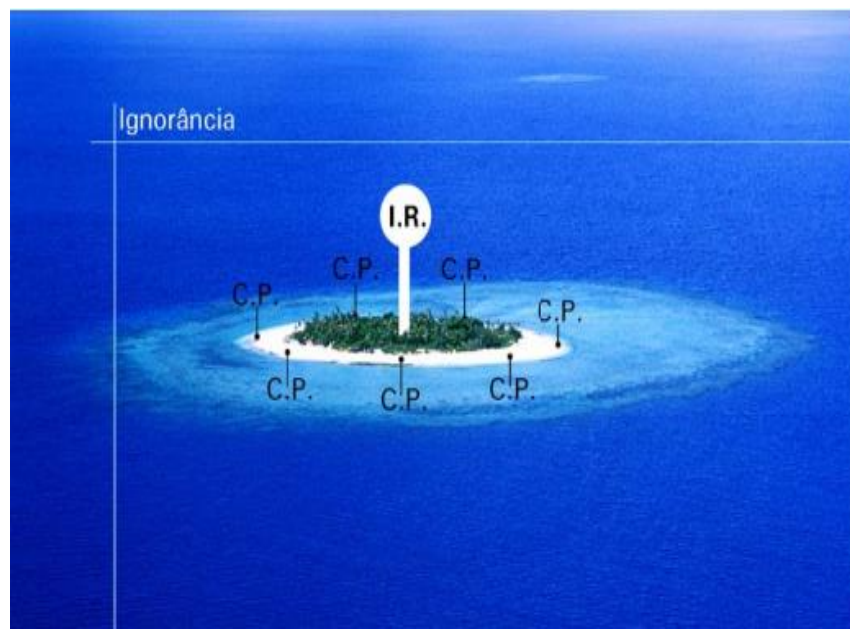

Fonte: Pietrocola e Alves Filho (1998).

Como metáfora, essa noção evoca conhecimentos que emergem num oceano de ignorância. Construindo uma Ilha de Racionalidade, nós sabemos que, para além do que será delimitado, nossas representações são "caixas pretas". A noção evoca também a racionalidade, no sentido de que o que se objetiva é um modelo discutível, modificável e eventualmente rejeitável, em função de sua pertinência face ao projeto estruturado (e não em função de uma verdade abstrata e/ou geral) (FOUREZ et al., 1997, p. 69-70).

Os autores descrevem dois tipos de Ilhas de Racionalidade - IR. A primeira é construída por intermédio de projetos, pautada em um problema específico que gera vários conhecimentos acerca daquela problemática. A segunda IR é construída a partir da noção sobre determinado assunto, "se trata de proporcionar uma representação multidisciplinar ao redor de noções frequentemente utilizadas em nossa cultura" (FOUREZ et al., 1997, p. 71). Contudo, os dois tipos de IR utilizam como temas geradores assuntos relacionados ao cotidiano do aluno, para aproximar as informações e os conteúdos de caráter científico da sua realidade. 
É necessário transformar a atitude, ousar na busca, mudar o olhar, quando tratamos de construção do conhecimento e do processo de ensino e aprendizagem. Uma vez que o professor assume o papel de mediador do conhecimento, utilizando-se da interdisciplinaridade em sala de aula, isso não significa que ele necessite conhecer todas as áreas do conhecimento igualmente, mas ter a iniciativa de criar estratégias e utilizar metodologias que envolvam múltiplos conhecimentos (FAZENDA apud MORO, 2015, p. 29).

Ao procurar referências sobre as IIR, foi possível constatar que essa ainda é uma metodologia pouco explorada, que, no entanto, apresenta resultados valiosos para quem busca o ensino por meio da pesquisa e da prática reflexiva. O lócus da pesquisa sobre trabalhos relacionados à IIR foi direcionado para o banco de dados da CAPES, onde foram localizadas ${ }^{10}$ somente 16 dissertações e 2 teses relacionadas a Ilhas Interdisciplinares de Racionalidade ou Ilha Interdisciplinar de Racionalidade no ensino de ciências.

O desafio lançado aos professores que pretendem desenvolver a IIR é transpor a barreira das disciplinas e considerar que o conhecimento, como algo significativo, dá-se de modo interdisciplinar; talvez por isso, o número de dissertações sobre a IIR não é tão expressivo. Fourez et al. (1997, p. 95, tradução nossa) explicam que "se pode considerar as disciplinas científicas como ilhas ou como continentes de racionalidade que têm sido organizados no curso de nossa história. Os mesmos estão construídos em arredores de imagens e paradigmas, mais ou menos clarificados".

Nas IIR, o professor não detém o saber. A metodologia e as etapas realizadas são moldadas por meio da mediação e da negociação, que exigem uma autonomia tanto da parte do aluno quanto do professor. Fourez et al. (1997) consideram que essa autonomia é desenvolvida durante o processo de alfabetização científica. Segundo Lucchesi (2010, p. 36), as IIR "permitem que o educando desenvolva capacidade de 'poder fazer', viabilizando, portanto, a crescente autonomia no processo de aprendizagem". Moro $(2015$, p. 114) considera que a IIR é "uma alternativa ao modelo de ensino-aprendizagem baseado na transmissão de informações fragmentadas, pois além de romper com o paradigma tradicional da sala de aula, podem propiciar a emergência de problemas que representam contextos reais".

Para a construção de uma IIR, Fourez et al. (1997) ${ }^{9}$ propõem oito etapas, que serão explanadas brevemente, com a intenção de situar o leitor. Essas etapas têm a função de orientar os passos a serem dados. Contudo, elas podem sofrer ajustes ou ser moldadas conforme a necessidade da turma, não sendo necessário executar todas as etapas. É também intencional fazer com que os alunos interfiram nesse processo de aprendizagem, opinando e optando sobre quais caminhos percorrer, exercendo, deste modo, a sua capacidade de tomada de decisão, diálogo, negociação e autonomia.

Além disso, alguns autores, como Bettanin (2003); Schmitz e Pinho-Alves (2004); Sousa e Brito (2007); Richetti (2008) e Leonel (2010), sugerem a elaboração da etapa zero, que corresponde à Organização Inicial. Para eles, nessa etapa ocorre o planejamento com relação aos objetivos, conteúdos e métodos, além de estabelecer os procedimentos para a avaliação. "É importante ressaltar que esta organização inicial deve ser entendida como sendo um ponto de referência, a fim de permitir modificações no decorrer da construção da IR". (SCHMITZ; PINHO- 
ALVES, 2004, p. 77). A seguir, apresenta-se as demais etapas propostas por Fourez et al. (1997), pontuadas por outros autores que corroboram com as suas ideias.

\section{ETAPA 1 - Elaboração do "Clichê"}

Nessa etapa, os alunos deverão elaborar questões, nas quais expressarão algumas dúvidas e concepções a respeito da situação-problema, que consiste no ponto de partida para o processo de investigação. Pode-se, também, fazer o levantamento do que inicialmente é necessário saber para poder iniciar o processo. É o "conjunto de representações (corretas ou errôneas) que a equipe de investigação tem da técnica" (FOUREZ et al., 1997, p. 113, tradução nossa). Bettanin (2003) ressalta que, nesta etapa, a curiosidade dos alunos abrange diversas áreas do conhecimento. Schmitz e Pinho-Alves (2004, p. 160) corroboram com a ideia:

No Clichê - a atitude pesquisadora, problematizadora, questionadora e os modos de ação interdisciplinar e dialético se tornam importantes para auxiliar os alunos a levantar questões sobre a situação problema. Atuar em tempo real e o uso de um outro recurso (além do professor participativo colaborador) para contextualizar e apresentar a situação problema pode ajudar nesta tarefa.

\section{ETAPA 2 - Panorama espontâneo}

Ampliação do clichê. Nesta etapa, ganha-se profundidade, ocorre o refinamento das questões e a organização dos próximos passos. É delimitada pelas seguintes ações: classificação das questões e formação dos grupos; busca de normas e condições impostas pela técnica; listagem dos atores envolvidos; lista dos Jogos de interesse e das tensões; listagem das caixas-pretas. Esta última é assim entendida por Schmitz e Pinho-Alves (2004, p. 101):

Uma caixa preta é uma noção no sentido de conteúdo/conhecimento ou um dispositivo dos quais não é necessário saber tudo para utilizá-la (é uma série de coisas que podemos ignorar e que nos permite levar a situação adiante). Elas são subsistemas materiais ou conceituais que se pode estudar em maior profundidade ou, ao contrário, deixar de examinar.

Continuando a lista de ações, temos ainda: a lista de bifurcações, que "designa um momento em que um ator social - por exemplo, um construtor, um vendedor ou um usuário - é levado a eleger uma estratégia em detrimento de outra" (FOUREZ et al., 1997, p. 115); e a lista de especialistas e especialidades pertinentes.

\section{ETAPA 3 - Consulta aos especialistas e especialidades}

Os alunos poderão consultar, se necessário, algum(ns) especialista(s) para esclarecer alguma(s) dúvida(s). Também poderá ocorrer a abertura das caixas pretas. Para Fourez et al. (1997), há uma coleção de informações que produz um enriquecimento da visão teórica dos alunos, o que levará a conhecer mais claramente $o$ assunto. Prestes evidencia que:

\footnotetext{
A consulta aos especialistas mostrou-se uma alternativa importante para a construção de novos argumentos. Para que os alunos pudessem consultar os especialistas, eles tiveram que elaborar melhor suas dúvidas, organizá-las, inclusive registrando-as por escrito. Os argumentos foram ficando cada vez 


\title{
ETAPA 4 - Descendo sobre o terreno
}

Nesta etapa, as equipes formadas saem do contexto teórico e vão à prática, visando ao aprofundamento da situação proposta. Segundo Fourez et al. (1997), existem várias maneiras de descer sobre o terreno: pode-se desmontar um equipamento, visitar lugares onde a tecnologia é utilizada, ler um folheto explicativo, artigos ou revistas, entrevistar um especialista, entre outros. Moro declara que:

\begin{abstract}
Nesta etapa, foi possível observar que a maior parte dos estudantes estava muito comprometida com a busca de conhecimento novo; a integração e a troca de informações entre os estudantes foram constantes. Também foi possível verificar que o objetivo de proporcionar aos estudantes o desenvolvimento da autonomia no processo de aprendizagem, incentivandoos a serem mais ativos na produção do conhecimento, foi cumprido no momento em que as equipes tomaram algumas decisões a respeito da pesquisa investigativa e procuraram esclarecer suas dúvidas da forma mais adequada para elas, buscando aprofundar seus conhecimentos com especialistas e por meio de pesquisa bibliográfica (MORO, 2015, p. 95).
\end{abstract}

\section{ETAPA 5}

Abertura aprofundada de algumas caixas-pretas e descoberta de princípios disciplinares que são a base de uma tecnologia. Etapa na qual há a possibilidade de trabalhar alguma disciplina específica. Um especialista pode auxiliar na abertura da caixa-preta "[...] contudo, as caixas pretas interessantes não são todas de competência de uma ciência da natureza; se pode também consultar uma especialidade vinculada a uma ciência humana [...]" (FOUREZ et al., 1997, p. 118). Cada estudo é selecionado em função do contexto, do projeto, dos produtores e dos destinatários da ilha de racionalidade.

\section{ETAPA 6 - Esquematização Global da Tecnologia}

Constitui-se na elaboração de uma síntese parcial a respeito do que já foi produzido na IIR, com a intenção de verificar o que já foi aprendido e o aprofundamento do assunto; representa teoricamente a situação. Ex: Elaboração de um texto, representação por meio de desenhos, uma exposição oral. "Ao longo de todo o percurso proposto, as representações que os participantes tinham da situação estudada vão modificando-se, seja por aportes do panorama, seja pelos especialistas ou ao longo das ações propostas" (CARNEIRO, 2016, p. 58). Para Fourez et al. (1997, p.127), essa etapa proporciona uma representação teórica da IIR.

\section{ETAPA 7 - Abrir algumas Caixas Pretas sem a ajuda de Especialistas}

Segundo Fourez et al. (1997), ninguém é capaz de entender todos os mecanismos técnicos sem ajuda dos especialistas. Contudo, o aluno deve ser levado a construir uma representação sobre alguma coisa, ou seja, diante do problema apresentado.

Esta etapa é significativamente importante na proposta das IIR, sobretudo do ponto de vista pedagógico. Em situações concretas, as pessoas usam conhecimentos disponíveis, já que não têm à mão todos os recursos - pessoas, livros etc. - com os quais poderiam interpretar a realidade mais adequadamente "[...] Neste momento, os estudantes podem avaliar, tomar decisões a respeito dos resultados obtidos, exercitando sua autonomia [...]" (SOUSA; BRITO, 2007, p. 54). 


\section{ETAPA 8 - Síntese da llha de Racionalidade Produzida}

Nessa etapa, Bettanin (2003) enfatiza que os materiais utilizados para a elaboração da síntese final revelam a criatividade e o espírito inventivo dos alunos. A síntese pode ser oral ou escrita e esse produto final da IIR, segundo Fourez et al. (1997), deve responder às seguintes perguntas:

- O que estudamos ajuda-nos a "negociar" com o mundo tecnológico examinado?

- Ele nos deu certa autonomia no mundo cientifico-técnico na sociedade em geral?

- Em que os saberes obtidos nos ajudam a discutir com mais precisão quando da tomada de decisões?

- Em que isto nos dá uma representação de nosso mundo e de nossa história que nos permite melhor situar-nos e fornecer uma real possibilidade de comunicação com os outros?

A síntese é o produto final da pesquisa que foi desenvolvida, reflete o que os alunos conseguiram aprender e de que forma são capazes de expressar esse aprendizado. Kindlein (2013) relata que na síntese é possível perceber que os alunos conseguem relacionar os conceitos científicos com conhecimentos e valores de diversas áreas, expondo seus argumentos e apresentando decisões responsáveis com base nos estudos realizados. Portanto, considera-se que a síntese deve fazer parte do processo avaliativo como um dos instrumentos para coleta de dados.

\section{CONSIDERAÇÕES FINAIS}

Ao mesmo passo que o enfoque CTS se configura como um caminho em direção ao desenvolvimento crítico dos alunos, alguns elementos - como a própria formação inicial dos professores, fundamentada na pedagogia tradicional; o currículo extenso e o material de apoio para os estudos, que por vezes se resume ao livro didático - podem dificultar a adoção dessa prática. Contudo, é válido ressaltar que, como forma de enfrentar os problemas sociais, existe, no campo da educação, a necessidade de um ensino contextualizado e ativo. Nessa conjuntura, o enfoque CTS se encontra com a metodologia proposta na Ilha Interdisciplinar de Racionalidade, a qual, por meio da pesquisa, favorece ao aluno o ato de questionar, refletir, propor soluções, repensar e argumentar.

No que diz respeito ao ensino de ciências, trata-se de um propósito pensar as implicações científicas e tecnológicas dentro da conjuntura social, questionando a neutralidade científica e formando cidadãos críticos. O enfoque CTS associado à IIR propõe-se a romper com o paradigma da reprodução do conhecimento, favorecendo a formação humana, viabilizando a relação entre o cotidiano do aluno e as transformações no campo da tecnologia, motivando um olhar crítico e reflexivo perante o desenvolvimento científico.

A ideia das llhas está relacionada ao conhecimento que possuímos diante do mar de informação que é possível alcançar. Desta forma, a IIR não se desenvolve apenas no ambiente escolar e para o ensino de ciências, ela representa uma epistemologia no modo de pensar e ensinar o saber científico. Para Fourez et al. 
(1997, p. 69), a ilha "se trata de inventar, frente a um projeto, uma modernização adequada, suficientemente simples, mas que utilize conhecimento proveniente de diversas disciplinas - e também dos saberes da vida cotidiana - indispensáveis nas práticas concretas".

O enfoque CTS e a IIR destacam o protagonismo do aluno no processo de ensino e aprendizagem. Por meio de uma metodologia desafiadora e estimulante retiram o aluno da posição passiva e receptora - marcante no ensino tradicional e direcionam-no para a construção do seu próprio conhecimento, que se solidifica na pesquisa, na investigação da situação-problema, na troca de informações e no diálogo com o outro para apresentar uma solução, ou seja, permite a eles o exercício da capacidade crítica. 


\title{
SCIENCE TEACHING: THE CTS APPROACH AND THE INTERDISCIPLINARY ISLAND OF RATIONALITY (IIR)
}

\begin{abstract}
The present theoretical research, carried out through a bibliographic study, aims to stimulate the debate about a still unusual methodology, the Interdisciplinary Island of Rationality (IIR). In it, I share reflections on science teaching with an emphasis on the focus on Science, Technology and Society (CTS). I report that, when traveling between the paths taken by science teaching, I found some pedagogical concepts that guided and others that still guide the methodology, curriculum and practice of teachers. In search of a strategy that would satisfy my desires regarding teaching strategies that would make critical and participatory teaching possible, I continued the trip and landed on the CTS "platform", where I was kindly invited to take shelter in that space. I accepted the invitation and set out to learn more about the ideas of those who were there; I enjoyed the knowledge of important characters; I learned a lot from the other participants and then decided, in the hope of also becoming a protagonist of this plot, looking for something different, that could help me find answers on how to make scientific and technological literacy effective. On that occasion, I was introduced to the Interdisciplinary Islands of Rationality. Complex strategy? Perhaps. However, very interesting and enriching. In this way, I dedicated myself to understand it better and, in this article, I share the findings of that pleasant stay on that "platform", where I could consider that, in addition to being a challenging methodology, the CST approach and IIR show valuable results for the current scenario in the face of science education, which aims to train subjects capable of interpreting the world in which they live and make informed decisions regarding social problems that are also of a scientific nature.
\end{abstract}

KEYWORDS: Science teaching. CTS. Interdisciplinary Island of Rationality. 
1 Os programas que influenciaram diretamente o ensino de Física, Química e Biologia foram o PSSC (Physical Science Study Commitee), BSCS (Biological Science Curriculum Study) e o CBA (Chemical Bond Approach).

2 Segundo Garcia, Cerezo e López (2000), nesse modelo linear, o desenvolvimento científico (DC) gera o desenvolvimento tecnológico (DT); este gera o desenvolvimento econômico (DE) que determina, por sua vez, o desenvolvimento social (DS - bem-estar social). DC $\rightarrow$ DT $\rightarrow$ DE $\rightarrow$ DS (modelo linear/tradicional de progresso)

3 Filósofo, físico e historiador que, nessa obra, questiona os paradigmas científicos.

4 Nessa obra, a autora denuncia as consequências trazidas pelo uso de inseticidas.

5 CTSA (Ciência, Tecnologia, Sociedade e Ambiente); alguns autores, como Silva e Araújo (2011), utilizam a sigla CTSA ao invés de CTS para enfatizar as questões ambientais. Na presente pesquisa, utiliza-se a sigla CTS, assim como Von Linsingen (2006), Santos e Mortimer (2007) e Santos e Schnetzler (2010).

6 Ensino através de temas, Microtemas, Temas Geradores e Ilhas Interdisciplinares de Racionalidade.

7 Auler e Delizoicov (2001) colocam como mito a Superioridade do modelo de decisões tecnocráticas; a Perspectiva salvacionista da CT e o Determinismo Tecnológico.

80 último acesso foi realizado em 8 de abril de 2020.

9 Para leitura na íntegra sugere-se o livro: Alfabetización científica y tecnológica. Acerca de lãs finalidades de la enseñanza de las ciencias, Ediciones Colihue (FOUREZ et al., 1997).

\section{REFERÊNCIAS}

AULER, D. Movimento Ciência-Tecnologia-Sociedade (CTS): modalidades, problemas e perspectivas em sua Implementação no ensino de física. In: Encontro de Pesquisa em Ensino de Física. 6, Resumos..., Florianópolis, 1998.

AULER, D.; BAZZO, W. A. Reflexões para a implementação do movimento CTS no contexto educacional brasileiro. In: Revista Ciência \& Educação. v.7, n.1, p. 1-13, 2001.

AULER, D.; DELIZOICOV, D. Ciência-tecnologia-sociedade: relações estabelecidas por professores de ciências. In: Revista Electrónica de Enseñanza de lãs Ciencias, Espanha, v. 5, n. 2, p. 337-355, 2006.

BAZZO, W. A.; LINSINGEN, I. V.; PEREIRA, L. T. V. Introdução aos estudos CTS 
BETTANIN, E. As ilhas de racionalidade na promoção dos objetivos da alfabetização científica e técnica. $160 \mathrm{f}$. Dissertação (Mestrado) - Curso de Educação, Centro de Ciências da Educação, Universidade Federal de Santa Catarina, Florianópolis, 2003.

BRITO, L. P. de; GOMES, N. F. O ensino de física através de temas no atual cenário do ensino de ciências. In: Encontro de Pesquisadores em Educação em Ciências. 6, 2007. Anais eletrônicos..., Florianópolis, 2007.

BRITO, L. P. de. Notas de aula da Disciplina: Tópicos especiais em Física: Tecnologia e Sociedade. UFPA/PPGECM/IEMCI, 2016.

CACHAPUZ et al. Do Estado da Arte da Pesquisa em Educação em Ciências: Linhas de Pesquisa e o Caso "Ciência-Tecnologia-Sociedade". Alexandria - Revista de Educação em Ciência e Tecnologia, v.1, n.1, p. 27-49, mar. 2008.

CARNEIRO, G. A. A interação museu-escola sob o referencial teórico metodológico das ilhas interdisciplinares de racionalidade. 165f. Dissertação (Mestrado) - Faculdade de Ciências, Universidade Estadual Paulista "Júlio de Mesquita Filho", Bauru, 2016.

CHASSOT, A. Ensino de Ciências no começo da segunda metade do século da tecnologia. In: LOPES, A. C.; MACEDO, E. (Orgs.). Currículo de Ciências em debate. São Paulo: Papirus, 2004.

DÍAZ, J. A. A.; ALONSO, Á. V.; MAS, M. A. M. Papel de la educación CTS en una alfabetización científica y tecnológica para todas las personas. In: Revista Electrónica de Enseñanza de Las Ciencias. [s.i], v. 2, n. 2, p.80-111, 2003.

FOUREZ, G. et al. Alfabetización científica y tecnológica. Acerca de las finalidades de la enseñanza de las ciencias. Buenos Aires, Argentina: Ediciones Colihue, 1997.

KRASILCHIK, M. REFORMAS E REALIDADE: o caso do ensino das ciências. São Paulo em Perspectiva, São Paulo, v. 1, n. 14, p.85-93, 2000. Trimestral.

LEONEL, A. A. Nanociência e nanotecnologia: Uma proposta de llha interdisciplinar de racionalidade para o ensino de física moderna e contemporânea no ensino médio. 215f. Dissertação (Mestrado) - Centro de Ciências da Educação, Universidade Federal de Santa Catarina, Florianópolis, 2010. 
MORO, E. da C. Ilhas Interdisciplinares de Racionalidade promovendo aprendizagem ativa. 143f. Dissertação (Mestrado) - Universidade de Caxias do Sul, Caxias do Sul, 2015.

NASCIMENTO, F. do; FERNANDES, H. L.; MENDONÇA. V. de M. O ensino de Ciências no Brasil: História, formação de professores e desafios atuais. In: Revista HISREDBR On-line. Faculdade de Educação Unicamp, Campinas, v. 10, n. 39, set. 2010.

PEREIRA, R. S.; MOREIRA, E. C. (Org.). A difícil tarefa de avaliar: possibilidades na educação física escolar. In: PEREIRA, R. S.; MOREIRA, E. C. Educação Física Escolar: desafios e propostas 2. 2. ed. [s.i]: Fontoura, 2011. Cap. 14. p. 271-288.

PIETROCOLA, M.; ALVES FILHO, J.P. Material de aula: Programa Pró-ciências, 1998.

PRESTES, R. F. Análise das contribuições do educar pela pesquisa no estudo das fontes de energia. 140f. Dissertação (Mestrado) - Faculdade de Física, Pontifícia Universidade Católica do Rio Grande do Sul, Porto Alegre. 2008.

RICARDO, E. C. Educação CTSA: obstáculos e possibilidades para sua implementação no contexto escolar. In: Ciência \& Ensino. v. 1, número especial, 2007.

RICHETTI, G. P. A automedicação como tema social no ensino de química para o desenvolvimento da alfabetização científica e tecnológica. 190f. Dissertação (Mestrado) - Centro de Ciências da educação, Universidade Federal de Santa Catarina, Florianópolis, 2008.

ROEHRIG, S. A. G.; CAMARGO, S. A educação com enfoque CTS no quadro das tendências de pesquisa em ensino de ciências: algumas reflexões sobre o contexto brasileiro atual. Revista Brasileira de Ensino de Ciência e Tecnologia, Ponta Grossa, v. 6, n. 2, p. 117-131, 2013.

SANTOS, W. L. P.; MORTIMER, E. F. Tomada de decisão para ação social responsável no ensino de ciências. Ciência \& Educação, Bauru, v. 1, n. 7, p.95111, 2001.

SANTOS, W. L. P.; SCHNETZLER, R. P. Educação em Química: compromisso com a cidadania. 4. ed. ver. atual. ljuí: Ed. Unijuí, 2010. 160p. (Coleção Educação em Química). 
SCHMITZ, C.; PINHO-ALVES, J. Ilha de Racionalidade e a situação problema: o desafio inicial. In: Encontro de Pesquisa em Ensino de Física. 9, 2004, Jaboticatubas. Ata em CD-Rom... Jaboticatubas: SBF, 2004.

SILVA, P. A. V. B.; ARAÚJO, M. S. T. Abordagem de temas de Educação Ambiental sob o enfoque CTSA no Ensino Médio. In: XIX Simpósio Nacional de Ensino de Física - SNEF, 2011.

SOUSA, R. G. Desafios, potencialidades e compromissos de uma experiência pedagógica para a formação cidadã: prática CTS construída a partir de uma ilha interdisciplinar de racionalidade sobre reciclagem do lixo urbano. 2007. $196 \mathrm{f}$. Dissertação (Mestrado) - Universidade Federal do Pará, Núcleo Pedagógico de Apoio ao Desenvolvimento Científico, Belém, 2007. Programa de Pós-Graduação em Educação em Ciências e Matemáticas.

SOUSA, R. G.; BRITO, L. P. Desafios de uma prática CTS construída a partir de uma Ilha de Racionalidade sobre reciclagem do lixo urbano. In: VI Encontro Nacional de Pesquisa em Educação em Ciências. 2007, Florianópolis. VI ENPEC, 2007.

TEIXEIRA, P. M. M. Educação Científica e Movimento C.T.S. no quadro das tendências pedagógicas no Brasil. Revista Brasileira de Pesquisa em Educação em Ciências, S. L., v. 1, n. 3, p.88-102, 2003. Anual.

Recebido: 27 mai. 2019

Aprovado: 23 abr. 2020

DOI: $10.3895 /$ rbect.v13n3.10155

Como citar: SOUZA, N. S. B; ALMEIDA, A. C. P. C. Ensino de Ciências: O Enfoque CTS e a llha

Interdisciplinar de Racionalidade (IIR). Revista Brasileira de Ensino de Ciência e Tecnologia, Ponta

Grossa, v.13, n. 3, p. 150-167, set./dez. 2020. Disponível em:

<https://periodicos.utfpr.edu.br/rbect/article/view/10155>. Acesso em: XXX.

Correspondência: Nely Soraya Bahia Souza- nelysoraya@hotmail.com

Direito autoral: Este artigo está licenciado sob os termos da Licença Creative Commons-Atribuição 4.0 Internacional. 